\title{
Tusk or Bone? An Example of Ivory Substitute in the Wildlife Trade
}

\author{
Margaret E. Sims, Barry W. Baker, \& Robert M. Hoesch \\ Author Address: U.S. National Fish and Wildlife Forensics Laboratory (NFWFL), 1490 E. Main St. Ashland, OR 97520 \\ cookiesims@fws.gov
}

Received: May $6^{\text {th }} 2011$

Published: August $14^{\text {th }} 2011$

Volume 2:40-44

(C) 2011 Society of Ethnobiology

\begin{abstract}
Bone carvings (and other ivory substitutes) are common in the modern-day lucrative international ivory trade. Souvenirs for unknowing travelers and market shoppers can be made of non-biological material (plastic "ivory" beads) or skillfully crafted natural objects made to resemble something other than their true origin. Many of these items are received at the U. S. National Fish and Wildlife Forensics Laboratory (NFWFL) for species identification as part of law enforcement investigations. Morphologists at the Lab often receive uniquely carved ivory items that have been imported with little or no documentation. In recent years, analysts examined several purported ivory tusks suspected to be walrus, a protected marine mammal. After examination, the Lab determined their origin as carved leg bones of cattle using principles and methods of zooarchaeology and ancient DNA analysis. The naturally long and straight ungulate metapodials had been cut, carved, filled, stained, and polished to closely resemble unmodified ivory tusks. Morphological species identification of these bones proved to be a challenge since diagnostic characters of the bones had been altered and country of origin was unknown. Genetic analysis showed that the bones originated from cattle. While bone is commonly used as a substitute for ivory, this style of artifact was not previously documented in the wildlife trade prior to our analysis. Archaeological ethnobiologists commonly encounter bone tools and other forms of material culture from prehistoric and historic contexts; in this case bone tools come from a modern context, thus the application of methods common in zooarchaeology are situated in wildlife forensics. In addition, results reported here pertain to cross-cultural ivory trade and conservation science.
\end{abstract}

Key Words: imitation ivory, bone, Bos taurus, wildlife trade

\section{Introduction}

The NFWFL functions as scientific analytical support of the law enforcement efforts of the United States Fish and Wildlife Service (USFWS) to uphold state, federal, and international wildlife laws and treaties. Unfortunately, illegal or improperly declared wildlife parts and products are routinely discovered in personal luggage, mail, and commercial shipments by inspectors at ports of entry to the U.S. Confiscated items ${ }^{1}$ were submitted to analysts at the National Fish and Wildlife Forensic Laboratory for species identification as a paired set of ivory tusks (Figure 1 Bottom, single tusk pictured). The items were assigned to the Morphology Section of the Lab to be identified using ivory identification techniques previously described (Espinoza and Mann 2000). The items were examined visually, and identification was made by macroscopic comparison with reference to a collection of known reference materials and published literature. No documentation of their origin was provided at the time of analysis.
Bone has been used as a natural ivory substitute for decades, and bone tools in general were used extensively by prehistoric peoples for thousands of years (Shell 1983, Krzyszkowska 1990). Bone has even been called the "poor man's ivory" (Abrams 1987). It is no surprise that bone material continues to appear in wildlife forensic casework. Evidence received at the NFWFL often includes bone jewelry, decorative boxes, statues, and modified artifacts (Figure 1). Although the material is light in color and can be polished to a smooth surface, the structure of bone is different from ivory.

Although ivory (carvable dentine) and bone share similar chemistry, ivory is a denser material ( $\mathrm{S}$. O'Connor, 1984; T. P. O’Connor 1984). It appears smooth without visible texture irregularities. Unlike ivory, bone is highly vascularized. The microscopic canals (Haversian system) within the bone matrix gives carved objects a "grainy" appearance. The fine pits and canals are naturally darker than the surrounding matrix, and are observed as fine dark spots, scratches, or irregular streaking on a carved object (Figure 1A). 


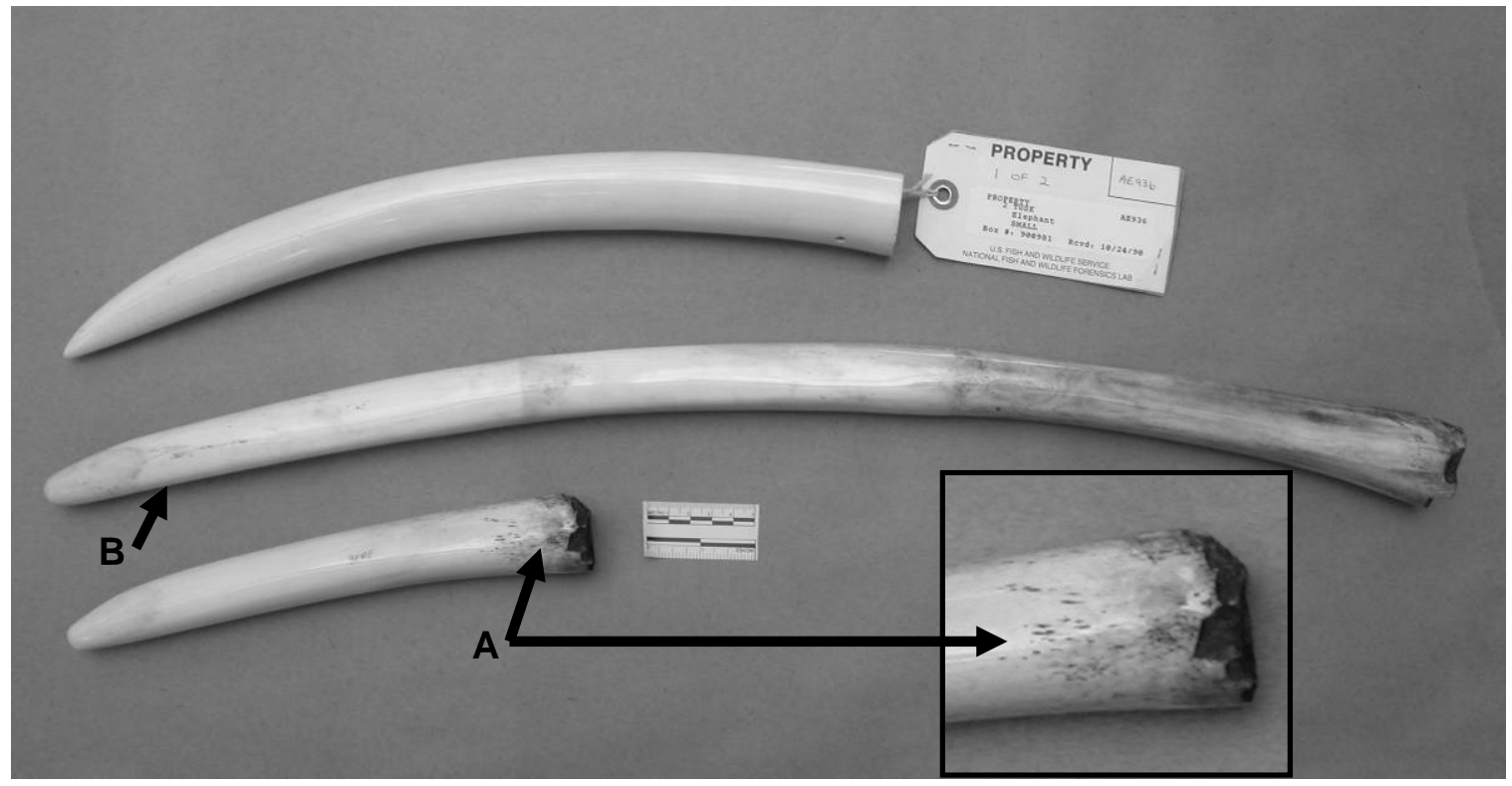

Figure 1. Top: small polished elephant tusk; Middle: fake ivory tusk constructed from long bones attached end-to-end; Bottom: fake ivory tusk made of bone. A: Diagnostic pitting on bone surface. B: Discoloration line where distal diaphysis is filled with amalgam.

(2003) and Locke (2004). Compact bone is most often used as an ivory substitute (Espinoza and Mann 2000). Cancellous bone, commonly found near the ends of long bones, has a sponge-like appearance and has much larger canals than smooth compact bone. It is the differences in these physical properties that distinguish ivory and bone when examining carved objects. Because ivory and bone share similar chemistry, they both fluoresce when examined with UV light (Espinoza and Mann 2000).

\section{Morphological Observations}

Although the size and color of the submitted items are similar to some ivory tusks found in the wildlife trade, these bone "tusks" are readily recognizable as fake. Further morphological analysis showed that they are carved leg bones (metatarsals) of a large bovid. The Haversian canals diagnostic for bone are clearly visible (Figure 1A). In addition, the items lack typical tusk features such as enamel, cementum, or a pulp cavity. The objects lack prominent Schreger morphology typical of extant and extinct elephants, and prominent secondary dentine observed in walrus ivory. The items also do not show the external longitudinal ridges and fine concentric dentine rings of hippopotamus incisors. The edges of the proximal epiphysis of the metatarsal have been chiseled away, leaving remnants of the articular surface visible and exposing cancellous bone (Figure 2).

The proximal ends of these items are stained dark brown to resemble tooth root discoloration. The bone shaft has been carved and polished to obtain a smooth shiny surface. Small nutrient canals (or their remnants) are visible on the distal anterior surface of the bone shaft. The distal epiphysis has been removed and filled-in with an amalgam. A slight discoloration in material (and appearance of texture) reveals where the bone ends and the amalgam begins (Figure 1B). The distal end was then rounded to form a tip and polished smooth. The result is a tusk-like object originally carved from a long bone.

The bone element was identified by the shape of the articular surface. The characteristic shape of an ungulate metatarsal articular surface (as compared with the smaller " $D$ " shape of a metacarpal) was visible even though the proximal end had been altered (Figure 2) (Gilbert 1990). The length of the bone and relative position of the nutrient foramina were helpful in identifying the bone to the lowest taxonomic level possible given the condition of the evidence. These features eliminated many comparable ungulate species including elk, moose, bighorn sheep, and camel. The carved metatarsals were most similar to a large bovid, which based on its upper shaft diameter (approximately $32 \mathrm{~mm}$ ) suggests domestic cow (Bos taurus), a species often used as a legal and ready source for bone material in the wildlife trade.

\section{Genetic Obervations}

To further determine the taxonomic origin of the bone used to fabricate these fake tusks, a small amount of bone material ( $\sim$ g.) was removed from each of two 

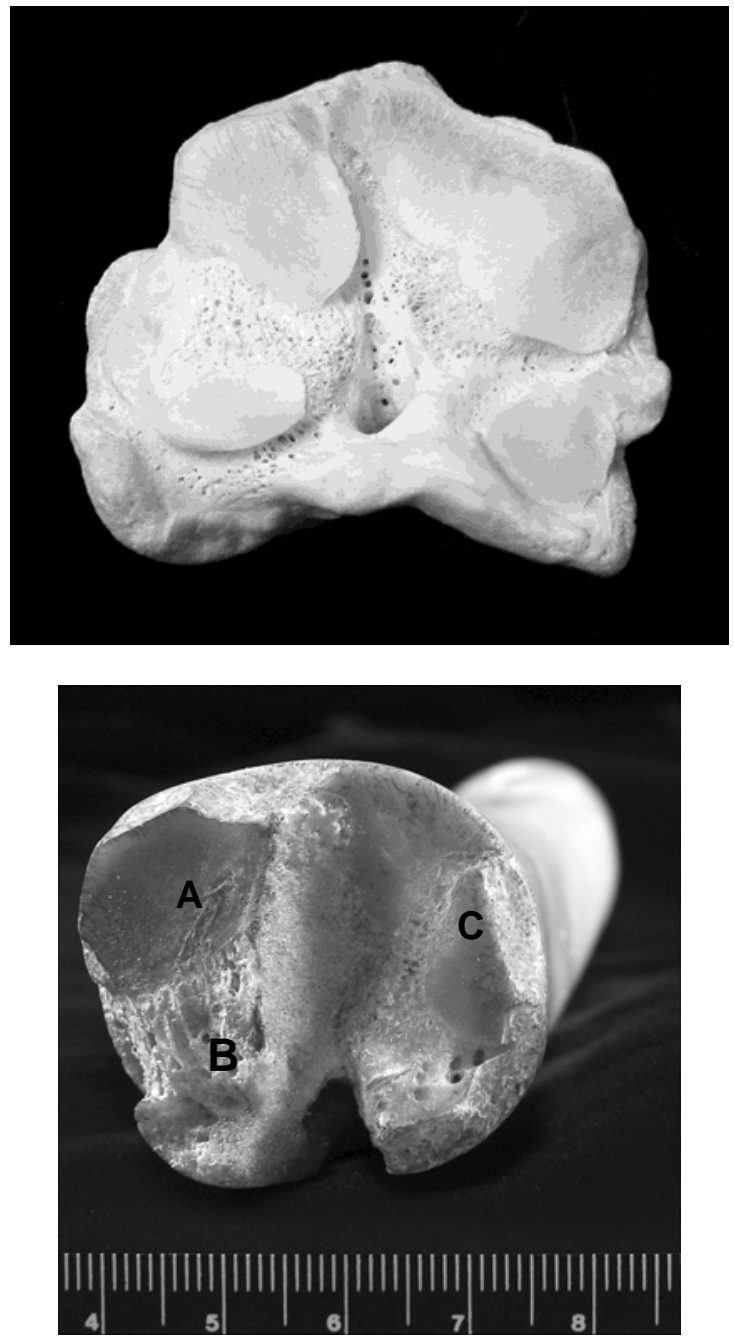

Figure 2. Top: proximal articular surface of cow metatarsal; Bottom: Metatarsal bone (fake ivory tusk) with heavy alteration. Most of the original articular surface has been obliterated. A: articular surface; B: cancellous bone; $\mathrm{C}$ : edge of tool mark from carving.

items and pulverized in a freezer mill. ${ }^{2}$ DNA was extracted from the pulverized bone using a commercial membrane-binding method (Nucleospin Tissue Kit, Machery-Nagel, Bethelehem, PA) ${ }^{2}$ and quantitated spectrophotometrically. The polymerase chain reaction was used to obtain a 265 base pair amplicon from the cytochrome $b$ gene. The amplicon was sequenced using cycle sequencing (Big Dye Terminator v. 3.1 Cycle Sequencing Kit, Applied Biosystems, Carlsbad, $\mathrm{CA})^{2}$, and analyzed using an ABI 3130xl Genetic Analyzer $)^{2}$. The resulting sequences were identical to domestic cow (Bos taurus), GenBank sequence DQ124403, positions 14,308 through 14,573, and also identical to Bos frontalis GenBank sequence EF061230.
Bos taurus is synonymous with Bos indicus (Bos taurus indicus) (Wilson and Reeder 2005).

\section{Discussion}

Morphological analysis revealed the items to be carved mammal long bones (metatarsals), rather than any source of commercial ivory such as walrus, elephant, or hippopotamus. Upon later discussion with law enforcement wildlife inspectors, the shipment origin of one of the fakes was discovered to be Hong Kong, one of the largest ivory-trading markets (Martin 2006) where bone-fabricated items are part of the industry. Cow bone is used extensively as an alternative carving material to ivory and is more common than other sources (Martin 2000). Genetic analysis of these fake tusks identified the source as cattle. Worldwide, there are many different cattle types, including domesticated and feral animals of different species within the family Bovidae. There are multiple specific types of cattle that may be available as raw materials and may be categorized as "cow."

Since our initial examination, additional fake tusks have been submitted to the Laboratory for analysis from ports on the east and west coast of the United States, including an elongated "tusk" constructed from several long bones attached together from end to end (Figure 1 Middle). It is not certain that metatarsals are used exclusively, as many of the articular surfaces have been heavily modified. Further analysis of additional evidence items was not pursued due to lack of probative value in forensic investigations.

The use of bone as a substitute in the commercial ivory trade has a long history, and such fake artifacts are common in the world of antiquities. However, we continue to be intrigued by the manufacturing details and considerable workmanship effort that goes into the numerous fakes and frauds seen in wildlife trade. While bone is commonly used as a substitute for ivory, this style of artifact was not previously documented in the wildlife trade prior to our analysis.

As a result of this analysis and the continued appearance of these items in the wildlife trade, an online identification guide was developed to assist field law enforcement officers in examining these fakes (Sims and Baker 2006). New USFWS Wildlife Inspectors are also trained annually in the identification of ivory and bone in order to examine the broad variety of artifacts imported regularly.

Growing international communities in the United States create new markets and global traffic for familiar goods that are new to western culture. Although we're unsure of how these items are marketed commercially 
in Asian culture, there are tourist images showing similar objects. Two fabricated "tusks" were observed for sale at the heavily-touristed Chatuchak market in Bangkok, Thailand by one of the authors (MES) in 2006. It is possible these carvings serve a dual purpose, partially modified and sold as souvenirs in the tourist market and sold as pipes in local markets for a functional purpose (ICITAP ${ }^{3}$ participants, personal communication, April 2010).

Morphological examination in this case proved useful in excluding the originally suspected ivory sources (walrus, hippo, and elephant tusk), and genetic analysis confirmed the crafted items were constructed from cattle bones. Prior to this analysis, this particular style of fake ivory artifact was not known in the wildlife trade. As international trade in wildlife parts and products continues to put pressure on alreadydwindling wild populations, it is likely that more commonly available resources (i.e., cattle bone) will be used to manufacture goods to satisfy consumer demand. While the use of bone, even from nonthreatened taxa, may engender the desire to have authentic animal products, it also remains an inexpensive alternative to true ivory, a practice that is promoted and encouraged by conservationists (Martin 2006). Training of inspectors and online identification aids continue to improve screening methods for imported shipments of undeclared or improperly declared wildlife material, and expedite inspections in support of legal possession and trade (i.e., bone objects from non-threatened species). As international trade in wildlife artifacts continues to expand, wildlife forensic scientists increasingly draw insight from subdisciplines within the field of ethnobiology as an aid to forensic analysis.

\section{Conclusion}

The U.S. Fish and Wildlife Service is responsible for both enforcing legislation regulating the trade in threatened and endangered species, and in facilitating the legal trade in wildlife. The artifacts described in this case study were purchased by buyers who believed they were authentic ivory that was confiscated by law enforcement officials who suspected the ivory to be authentic. Subsequent forensic analysis shows these items were, in fact, constructed from cattle bones. While bone is commonly used as a substitute for ivory (especially in small carvings), this particular style of whole fake "ivory tusk" was not previously known in the wildlife trade. This note serves to highlight this relatively new trend and to bring this awareness to ethnobiologists and law enforcement officials so that individuals are not wrongly charged with ivory trafficking. In this case, methods commonly applied by archaeological ethnobiologists to material culture from prehistoric contexts (e.g., bone and ivory tools) provide useful information relevant to wildlife forensics and conservation science.

\section{Acknowledgements}

We thank Darby Morrell for assistance with digital images, and various colleagues for reading earlier drafts of this paper. The findings and conclusions in this article are those of the author(s) and do not necessarily represent the views of the U.S. Fish and Wildlife Service.

\section{References Cited}

Abrams, H. N. 1987. Ivory: an International History and Illustrated Survey. Harry N. Abrams, Incorporated, New York, NY.

Espinoza, E. O. and Mann, M. J. 2000. Identification Guide for Ivory and Ivory Substitutes, $3^{\text {rd }}$ edition. Ivory Identification, Inc., Richmond, VA.

Gilbert, B. M. 1990. Mammalian Osteology. Missouri Archaeological Society, Columbia, MO.

Krzyszkowska, O. 1990. Ivory and Related Materials: an Illustrated Guide. Classical Handbook 3. Bulletin Supplement 59, Institute of Classical Studies, London, UK.

Locke, M. and R. L. Dean. 2003. Vascular Spaces in Compact Bone: A Technique to Correct a Common Misinterpretation of Structure. The American Biology Teacher 65:701-707.

Locke, M. 2004. Structure of Long Bones in Mammals. Journal of Morphology 262:546-565.

Martin, E. 2006. Are We Winning the Case for Ivory Substitutes in China? Pachyderm 40:89-101.

Martin, E. B. and Stiles, D. 2000. The Ivory Markets of Africa. Save the Elephants, Nairobi and London.

O'Connor, S. 1984. The Identification of Osseous and Keratinaceous Materials at York. In U.K.I.C. Archaeology Section Conference Proceedings, edited by K. Starling and D. Watkinson. pp 9-21. Institute for Conservation, London, UK.

O'Connor, T. P. 1984. On the Structure, Chemistry, and Decay of Bone, Antler, and Ivory. In U.K.I.C. Archaeology Section Conference Proceedings, edited by K. Starling and D. Watkinson. pp 6-8. Institute for Conservation, London, UK. 
Shell, H. 1983. Is it Ivory? Ahio Publishing Co, Tulsa, OK.

Sims, M. E. and B. W. Baker. 2006. Tusk or Bone?: An Example of Fake Walrus Ivory in the Wildlife Trade. Identification Guides for Wildlife Law Enforcement No. 10. USFWS, National Fish and Wildlife Forensics Laboratory, Ashland, OR.

Sweet, D. and D. Hildebrand. 1998. Recovery of DNA from Human Teeth by Cryogenic Grinding. Journal of Forensic Science 43:1199-1202

Wilson, D. E. and D. M. Reeder (eds.). 2005. Mammal Species of the World. A Taxonomic and Geographic Reference, $3^{\text {rd }}$ edition. Johns Hopkins University Press, Baltimore, MD.

\section{Biosketches}

Margaret E. Sims is a Forensic Scientist in the Morphology Section of the U.S. National Fish and Wildlife Forensics Laboratory. She completed her B.S. and M.S. at Southern Oregon University. Her current casework and research involves forensic identification of mammal remains.

Barry W. Baker is a Forensic Scientist in the Morphology Section of the U.S. National Fish and Wildlife Forensics Laboratory. He also serves as an adjunct professor of anthropology in the Department of Social Sciences, Policy, and Culture at Southern Oregon University. He completed his B.A. and M.A. at Texas A\&M University. His current work and research focuses on wildlife forensics, especially forensic morphology, forensic herpetology, and forensic mammalian osteology.

Robert M. Hoesch is a Forensic Scientist in the Genetics Section of the U.S. National Fish \& Wildlife Forensic Laboratory. He earned a Master's Degree from the University of Toledo (Ohio) and has done research at universities and medical colleges in the U.S.

\footnotetext{
${ }^{1}$ Specimens have been deposited for curation at the National Fish and Wildlife Forensics Laboratory in Ashland, Oregon.

${ }^{2}$ Use of commercial products does not imply U.S. Government endorsement.

${ }^{3}$ United States Department of Justice, Criminal Division, International Criminal Investigative Training Assistance Program (ICITAP).
} 